\title{
Plating/Nailing the Ideal Fixation for Diaphyseal Fractures of Humerus- Our Experience.
}

\author{
Dr, K. Kodandapani ${ }^{1}$, Dr. N. Ravindra Kumar ${ }^{2}$, Dr. Kali Vara Prasad \\ Vadlamani ${ }^{3}$, Dr. Anil Kumar ${ }^{4}$ \\ $\left({ }^{1,23}\right.$ Associate Professors, ${ }^{4}$ Senior Resident, Department Of Orthopedics And Traumatology, Osmania \\ Medical College/ Hospital, Hyderabad, Telengana).
}

\begin{abstract}
Background: The diaphyseal fractures of humerus were traditionally treated conservatively, but the needs of the patients warranted Surgical fixation of these fractures now. The two most popular methods of fixation are Plate Osteosynthesis and Intra-medullary fixation with Inter-locking Nail. In this study we tried to compare these two methods of fixation to arrive at the ideal choice of implant for these fractures. Permission of the Ethical committee

Materials \& Methods: In this study we included 38 patients with diaphyseal fractures of humerus, who attended the department of Orthopedics and Traumatology, Osmania General Hospital, Hyderabad. The period of study was 2 years i.e, from September 2013 to September 2015.

RESULTS : Among the 38 patients 10 had excellent results, 12 had good results, 10 had fair results, 6 had poor results.

Conclusion: Both the methods of fixation have their definitive indications, but if a similar fracture has to be fixed Plate Osteosynthesis is the method of choice.

Our sample size is small to make any emphatic statements, but the study is being continued and we will be coming out with a bigger sample size in future.

Keywords: Diaphyseal fractures, Plate fixation, Interlocking Nailing, Fracture Humerus.

Correspondance : Dr. Kali Vara Prasad Vadlamani, Associate Professor, F 12, Sneha Enclave, St No 4, West Maredpally, Secunderabad. Telengana State. Mail :
\end{abstract}

\section{Introduction}

Fractures of the humeral shaft are common and accounts for $3 \%$ of all fractures(20\% of all humerus fractures $)^{1}$.Fractures of humeral shaft have traditionally been regarded benign, with high percentage of primary healing with conservative methods, using either a hanging arm cast or functional brace. However loss of reduction in the plaster cast invariably leads to malunion. Operative treatment for humerus fractures has usually been reserved for the treatment of nonunion, associated with fractures of forearm, for polytrauma patients, and for those with neurovascular complications. The advantages of operative management are early mobilization . But, operative management carries the risk of technical errors and post operative complications infections, nerve injuries etc. Most of the studies have used fracture union as the major determinant of the outcome and very few studies have examined the functions at the shoulder and elbow joints. The optimal method of humeral shaft fracture fixation remains in debate. Two techniques under study include intramedullary nailing and plate osteosynthesis. Plating provides satisfactory results but requires extensive dissection, and meticulous radial nerve protection. The plate may fail in osteoporotic bone. With the dynamic success of intramedullary fixation of fractures of the femur and tibia, there was speculation that intramedullary nailing might be more appropriate for humeral shaft fractures than plating. The theoretical advantage of intramedullary nailing included less invasive surgery, an undisturbed fracture hematoma and use of a load sharing device support.

However, the phenomenal success of interlocking nailing in long bones like femur and tibia is not seen in humerus. According to recent studies the preferred method of fixation of humeral fractures is by plate osteosynthesis. The purpose of this study is to compare the outcomes of each method of fixation ( plating and interlocking nailing) for, the fracture shaft of humerus and to analyse statistically significant difference in the results of these two methods.

\section{Aims}

To compare the results of plate osteosynthesis and interlocking nailing in the treatment of fracture shaft of humerus with reference to,

- $\quad$ Rate of healing

- Functional outcome 
- Complications and

- Morbidity.

\section{Classification}

There is no universally accepted classification for humeral shaft fractures Classically they have been classified on the basis of factors that influence treatment like

Fracture location - Based on the part of the diaphysis involved it is classified as

Proximal-third

1. Middle-third.

2. Distal-third.

\section{Direction and character of fracture line}

1. Transverse

2. Oblique

3. Spiral

4. Segmental

5. Comminuted

AO/ASIF Classification - In this the fractures are divided into 3 types with further subdivisions.

A - Simple fracture.

A 1 - Spiral Fracture.

A 2 - Oblique fracture.

A 3 - Transverse fracture.

B - Wedge fractures.

B 1 - Spiral wedge.

B 2 - Bending wedge

B 3 - Fragmented wedge

C- Complex Fractures

C 1 - Complex spiral

C 2 - Complex segmental fractures

C 3 - Complex irregular fractures

This classification has prognostic value because higher fracture types have greater risk as they are high energy fractures. classification of the fracture guides us in choosing the treatment modality. A simple oblique fracture yields good results with conservative management. A transverse fracture precludes the use of hanging arm cast due to risk of distraction and potential complications ${ }^{2}$.spiral fractures in the distal third also called as Holstein - Lewis fracture is often complicated by Radial nerve palsy either primarily or post closed reduction ${ }^{3}$. Segmental fractures usually need internal fixation. Comminuted fracture are better managed by closed means. Osteopenic boned are better managed by intramedullary nailing than by plating

\section{Operative Treatment}

Though majority of the simple fracture are managed non operatively, specific indications exists for operative treatment ${ }^{4}$.the indications can be divided into fracture indications, associated injuries, and patient indication

\section{Fracture indications}

a) Failure to obtain and maintain adequate closed reduction.

a. Shortening greater than 3 centimeter.

b. Rotation greater than 30 degrees.

c. Angulation greater than 20 degrees.

b) Segmental fractures

c) Pathologic fractures.

d) Intra-articular extension.

a. Shoulder joint

b. Elbow joint.

\section{Associated injuries.}

a) Open wound. 
b) Vascular injury.

c) Brachial plexus injury. .

d) Ipsilateral forearm fractures.

e) Bilateral humeral fractures.

f) Lower extremity fractures requiring upper extremity weight bearing (Crutch walking). Burns.

h) High velocity gunshot injury.

i) Chronic associated joint stiffness of shoulder or elbow.

\section{Patient indications}

a) Polytrauma.

b) Head injury (Glasgow coma scale lesser than 8).

c) Chest trauma.

d) Poor patient tolerance.

e) Unfavorable body habitus Ex:-Morbid obesity.

f) Parkinson's disease and other neurological diseases ${ }^{5}$

The main methods employed for internal fixation of humeral shaft fractures are

1. plate and screws

2. Intramedullary nailing.

3. External fixation.

\section{Plate Osteosynthesis}

This is the gold standard for fixation of humeral shaft fractures ${ }^{6}$. Plating is associated with high union rate, low complications rate and rapid return to function. The plate is applied on the tension side of the bone in accordance with the tension band principle. In humerus the most commonly used plates are the Dynamic compression plate (DCP).

\section{Intra Medullary Interlocking Nail Fixation}

Closed medullary nailing of fractures of the humeral shaft is rapidly becoming the treatment of choice in multiple trauma patients, fractures with overlying burns, patients with osteoporotic bone, pathological fractures and segmental fractures. Interlocking medullary humeral nail fixation can be used in the treatment of fractures $3 \mathrm{cms}$ proximal to the olecranon to within $2 \mathrm{cms}$ of the surgical neck of the humerus. The interlocking nail can be inserted retrograde or ante grade and is designed for reamed and non reamed insertion. The nail is available in diameters of 7,8 and $9 \mathrm{~mm} .7 \mathrm{~mm}$ is solid, 8 and $9 \mathrm{~mm}$ nails are cannulated.

\section{Complications}

\section{Malunion}

Nonunion

Infected nonunion

Non unions with bone loss

\section{Neurological complications}

Vascular complications

\section{Materials And Methods}

This study was conducted in the Department of Orthopaedic surgery and traumatology at Osmania Medical College and Hospital, Hydeabad between September 2013 to September 2015.

During the above period patients with diaphyseal fractures of the humerus with indications for surgical management were included in the study.

\section{Inclusion criteria}

1. All fractures of diaphysis of humerus indicated for surgical treatment.

2. Patients of age 18 years and above

\section{Exclusion criteria}

1. Fracture of upper and lower ends of humerus

2. Patients treated with other than plate osteosynthesis or interlocking nail

3. Patients with pre existing shoulder and elbow problems.

4. Pathological fractures

5. Patients who were lost to follow up or died before the fracture union. 
The patients who met the inclusion and exclusion criteria were included in the study after taking informed consent. A thorough history and clinical examination was done. The status of radial nerve injury was recorded. Roentgenogram of the arm with shoulder and elbow was taken in both antero-posterior and lateral views. Additional roentgenograms were taken if any other injury was suspected. The humeral shaft fracture was temporarily immobilized with a U-slab and arm pouch.

We used either plate osteosynthesis(DCP/LC-DCP) or interlocking nail for 38 patients between September 2013 to september 2015. Osmania Medical College and Hospital, Hyderabad or stabilization of fracture of the humeral diaphysis.

The 38 humeri of these 38 patients were prospectively randomised into two categories of plate osteosynthesis or interlocking nailing. Once the patients were randomized, pre-operative planning and investigations were done and the patients were posted for open reduction and internal fixation with DCP/LCDCP or interlocking nailing.

Anterolateral approach was used in patients with fractures of the upper and middle thirds of the shaft of the humerus. Posterior approach was used in patients with fractures of the lower thirds of the shaft. Only antegrade nailing was done in case of interlocking nailing group.

In the first group, $4.5 \mathrm{~mm}$ narrow DCP/LC-DCP was used, and in second group standard intramedullary interlocking nail was used. 38 patients of the 38 fractures, 15 were fixed with DCP,3 patients with LC-DCP and 20 were fixed by interlocking nail.

The age of our patients varied from 22 years to 70 years, the average age was 36.7 years. There were 27 males and 11 females. 27 patients had suffered fractures in motor vehicle accidents, 3 were domestic injuries 7 were fall from height and 1 was sports injury. The right arm was involved in 23 patients and left arm in 15 patients. 3 patients had pre operative radial nerve palsy, out of which 2 patients recovered completely. The duration from injury to treatment varied from 1 to 11 days (average being 3.92 days).

The fractures of humerus were classified according to the AO classification system into AI, A2, A3, B1, $\mathrm{B} 2, \mathrm{~B} 3, \mathrm{Cl}, \mathrm{C} 2$, and $\mathrm{C} 3.3$ patients in $\mathrm{Al}$ group (simple spiral fracture), 5 in A2 group (oblique fracture with fracture angulation being $>$ or $=30$ degrees), 12 patients were in A3 (transverse fracture with fracture angle less than 30 degrees), 4 patients were in BI (spiral wedge fracture- $\{$ butteffly fragment $\}$ ), 7 patients were in B2 group (i.e. bending wedge), 1 patient in B3 group (fragmented wedge), 1 patient in $\mathrm{Cl}$ group ( complex spiral), 3 patients in $\mathrm{C} 2$ group ( complex segmental)and 2 patient in $\mathrm{C} 3$ group (communited irregular).

Among the 18 patients in the plating group the age varied from 22 to 60 years (average being 37.28 years). Posterior approach was used in 12 patients and an anterolateral approach was used for the remaining 4 patients. Among the 20 patients in the interlocking group, the age varied from 23 years to 70 years (average being 35.05 years). A $7 \mathrm{~mm}$ nail was used in 16 patients, whereas $6 \mathrm{~mm}$ nail was used for 4 patients. Only ante grade nailing was done in nailing group.

\section{Follow Up}

The patients were followed up every second week till radiological union was seen. At every follow up clinical examination was done to assess status of the surgical wound, pain, tenderness, range of motion of shoulder and elbow, stability of the fracture and clinical union. Roentgenograms were taken in AP and Lateral views to look for signs of radiological union.

In our study we concluded clinical union when the fracture site had become stable and pain free. The union is confirmed radiologically when plain X-ray showed bone trabaculae or cortical bone crossing fracture site on at least three surfaces on orthogonal radiograms. The time taken for clinical and radiological union was noted. If there are no clinical and radiological signs of union by 16 weeks, the fracture was categorised as delayed union and if absence of fracture union after 32 weeks after injury was categorized as non union. We had 2 cases of non union following plate osteosynthesis.

We encountered 3 patients who presented with a concomitant radial nerve palsy were examined in each visit and power was noted. Return of $5 / 5$ power was regarded as complete recovery.

The functional outcome was measured by the "Disabilities of Arm, Shoulder and Hand" (DASH) Questionnaire at nine months or at full recovery which ever was earlier. The Dash scoring system is a very useful tool to measure function of the upper limb developed by the American Academy of Orthopaedic Surgeons (AAOS) and has been validated by various, studies ${ }^{7,8,9}$

The DASH questionnaire has thirty questions the answers of which are graded from one to five points. The functional score is calculatred by the formula $\{[$ Sum of responses)-1\} DASH Dlsabzllty / Symptom Score $\mathrm{x} 25$

$\mathrm{N}$ 
Where ' $\mathbf{N}$ ' is the number of responses. The best possible score is ' $\mathbf{0}$ ' and the worst possible score is ' $\mathbf{1 0 0}^{\prime}$ '. The functional outcome decreases as the score increases. The result was then graded as Excellent, Good, Fair and Poor as follows

$\begin{array}{lll}\text { Excellent } & - & 0 \text { to } 20 \text { points } \\ \text { Good } & - & 21 \text { to } 40 \text { points } \\ \text { Fair } & - & 41 \text { to } 60 \text { points } \\ \text { Poor } & - & \text { Greater than } 60 \text { points }\end{array}$

The time taken for radiological union and the functional outcome in both groups were then compared.

The Dash Scoring System

DASH Score (Disabilities of arm, shoulder and hand questionnaire)

\begin{tabular}{|c|c|c|c|c|c|c|}
\hline & & No difficulty & No difficulty & $\begin{array}{l}\text { Moderate } \\
\text { difficulty }\end{array}$ & $\begin{array}{l}\text { Severe } \\
\text { difficulty }\end{array}$ & Unable \\
\hline 1 & Open a tight or a new jar & 1 & 2 & 3 & 4 & 5 \\
\hline 2 & Write & 1 & 2 & 3 & 4 & 5 \\
\hline 3 & Turn a key & 1 & 2 & 3 & 4 & 5 \\
\hline 4 & Prepare a meal & 1 & 2 & 3 & 4 & 5 \\
\hline 5 & Push open a heavy door & 1 & 2 & 3 & 4 & 5 \\
\hline 6 & Place an object on a shelf above your head & 1 & 2 & 3 & 4 & 5 \\
\hline 7 & Doing heavy household chores & 1 & 2 & 3 & 4 & 5 \\
\hline 8 & Gardening or doing yard work & 1 & 2 & 3 & 4 & 5 \\
\hline 9 & Making a bed & 1 & 2 & 3 & 4 & 5 \\
\hline 10 & Carrying a shoping bag or briefcase & 1 & 2 & 3 & 4 & 5 \\
\hline 11 & Carrying a heavy object (over 5 kilometer) & 1 & 2 & 3 & 4 & 5 \\
\hline 12 & Changing a light bulb overhead & 1 & 2 & 3 & 4 & 5 \\
\hline 13 & Washing or blowing drying the hair & 1 & 2 & 3 & 4 & 5 \\
\hline 14 & Washing the back & 1 & 2 & 3 & 4 & 5 \\
\hline 15 & Putting on a pullover & 1 & 2 & 3 & 4 & 5 \\
\hline 16 & Using a knife to cut food & 1 & 2 & 3 & 4 & 5 \\
\hline 17 & $\begin{array}{l}\text { Recreational activities that require liffle } \\
\text { efforts }\end{array}$ & 1 & 2 & 3 & 4 & 5 \\
\hline 18 & $\begin{array}{l}\text { Recreational activities in which you take } \\
\text { some force or impact through your arm } \\
\text { shoulder or hand (e.g. hammering tennis, } \\
\text { golf) }\end{array}$ & 1 & 2 & 3 & 4 & 5 \\
\hline 19 & $\begin{array}{l}\text { Recreational activities in which you move } \\
\text { your arm freely (e.gbadminton, throwball, } \\
\text { etc) }\end{array}$ & 1 & 2 & 3 & 4 & 5 \\
\hline 20 & Manage trasporation needs & 1 & 2 & 3 & 4 & 5 \\
\hline 21 & Sexual activities & 1 & 2 & 3 & 4 & 5 \\
\hline 22 & $\begin{array}{l}\text { During the past week, to what extent has } \\
\text { your arm shoulder or hand problem } \\
\text { interfered with your normal social activities } \\
\text { with family friends,neihbours or groups }\end{array}$ & 1 & 2 & 3 & 4 & 5 \\
\hline 23 & $\begin{array}{l}\text { During the past week, were you limited in } \\
\text { your work, or otherdaily activitiy as a result } \\
\text { of your arm, shoulder or hand problem }\end{array}$ & 1 & 2 & 3 & 4 & 5 \\
\hline 24 & Arm shoulder or hand pain & 1 & 2 & 3 & 4 & 5 \\
\hline 25 & $\begin{array}{l}\text { Arm shoulder or hand pain when you } \\
\text { perform any specific activity }\end{array}$ & 1 & 2 & 3 & 4 & 5 \\
\hline 26 & Tingling in your arm shoulder or hand & 1 & 2 & 3 & 4 & 5 \\
\hline 27 & Weakness in arm, shoulder or hand & 1 & 2 & 3 & 4 & 5 \\
\hline 28 & Stiffness in your arm shoulder or hand pain & 1 & 2 & 3 & 4 & 5 \\
\hline 29 & $\begin{array}{l}\text { During the past week, how much difficulty } \\
\text { have you had sleeping because of pain in } \\
\text { your arm shoulder and arm }\end{array}$ & 1 & 2 & 3 & 4 & 5 \\
\hline 30 & $\begin{array}{l}\text { I feel less capable less confident or less } \\
\text { useful because of my arm, shoulder, and } \\
\text { hand }\end{array}$ & 1 & 2 & 3 & 4 & 5 \\
\hline
\end{tabular}

\section{Results}

There were 38 fractures shaft of humerus in adults which presented to our hospital during the course of the study. The 38 patients with the distribution being 18 in plating, 20 in interlocking group( table \& graph 1 ).

There were 14 Males and 6 female patients in our study. ( table \& graph 2 ).

The age of the patients in the plating group ranged from 22 to 60 years with a mean of 37.* years. The age in the interlocking group ranged from 23 to 70 years with a mean age of 35.5 years. By applying the student 
' $\mathrm{t}$ ' test the ' $\mathrm{t}$ ' value came as 0.606 with $\mathrm{p}$ value of 0.549 ( $\mathrm{p}>0.05)$ which showed that there was no statistically significant difference in the age distribution of the two groups ( table \& graph 3 ).

The commonest mode of injury was RTA, followed by Fall and domestic accidents ( table \& graph 4). Right side was the most commonly involved side in both the plating and Interlocking group with no statistically significant difference ( table \& graph 5 ).21 fractures occurred in the middle third of the diaphysis. 11 in the interlocking group and 10 in the plating group. 9 fractures were there in lower third 3 fracture in the middle third and lower third junction. 3 fractures in the upper third. 1 fracture between upper third and middle third junction. 1 segmental fracture extending between upper third and lower third ( table \& graph 6).

DASH scores of 0 to 20 was taken as excellent, 21 cto 40 good, 41 to 50 was taken as fair and above 61 was taken as poor. The average DASH score of the whole series was 34.1 (lowe the DASH score better the function). The average DASH score in the plating group was 24.1 and in the interlocking group it was 43.1. the results were statistically significant with $\mathrm{p}$ value of 0.024 .

Among the 38 patients 10 had excellent results, 12 had good results, 10 had fair results, 6 had poor results ( table 7 ).

Intraoperative the interlocking group had 4 complications and the plating group had only 2 complications'

Postoperatively in the plating group there were 13 complications and in the interlocking group there were 6 cases with complications.

Complications were more in the interlocking group, which was statistically soignificant $(\mathrm{p}=0.009)$ ( table 8 and graph 7 ).

\section{Discussion}

Most surgeons agree that intramedullary nailing is the best internal fixation for femoral and tibial shaft fractures, but there is no agreement about the ideal procedure for fractures, of the humeral shaft. Plate osteosynthesis requires extensive soft tissue dissection with the risk of radial nerve damage ${ }^{10}$.

The indications for open reduction and internal fixation of acute fractures of the humeral shaft have been described as: fractures in patients with multiple injuries, open fractures, fractures associated with vascular or neural injuries or with lesions of the shoulder, elbow or forearm in the same limb; bilateral upper extremity injuries, fractures for which closed methods of treatment have failed and pathological fractures.

In several reported series, the presence of associated multiple injuries was the most frequent indication for internal fixation of the humeral shaft ${ }^{11,12,13,14,15}$. In our study failed closed reduction and associated injuries were the most common indications.

This study is having a short term follow up of minimum of 6 months and maximum of 17 months (mean 11.44months) and therefore discussion is essentially a preliminary assessment. In previous reports the incidence of non-union after plating has ranged from $2 \%$ to $4 \%{ }^{16,17}$. In our plating group the incidence of nonunion is $11.11 \%$. Retrospective studies of locked intramedullary nail fixation quote incidences of non-union ranging from $0 \%$ to $8 \% \%^{18,19,20,21,22}$. In our series the incidence of non- union in the interlocking nail group is $0 \%$.

The incidence of radial nerve palsy with fracture shaft humerus varies from $6 \%$ to $15 \%$. $13,24,25$. In our series the incidence was 7.9\%. Out of the 3cases, 2 cases recovered (66.6\%), which tallied with Seddon's and Pollock's series of $70 \%$ and $68 \%$ respectively. In the plating group the incidence of post operative radial nerve palsy is $2 \%$ to $5 \%$, but there were no such cases in our study.

Which was same in the case of the interlocking group. The incidence of post operative radial nerve palsy in various studies varies from $2.6 \%$ to $14.3 \%{ }^{, 26}$ in the interlocking group. There was no problem with infection in our patients with only 1 patient having superficial infection (2.63\%) among 38 patients, which responded well to debridement and intravenous antibiotics for 3 weeks.

The failure of fixation in a case of DCP was due to poor technique due to inadequate hold. When this fracture was replated with the addition of 2 extra holes and bone graft, the fracture united at 6 months without complications. The patient with implant failure in interlocking group went on to unite uneventfully despite the screw breakage at one of the two distal interlocking sites.

The rate of intra operative comminution during interlocking nail insertion with various studies varied from $7.7 \%$ to $10 \%$. In our series there were $2(10 \%)$ intra operative comminutions out of 20 patients treated with interlocking nailing. One occurred at fracture site due to hoop stress and the other at the greater tuberosity during nail insertion.

Persistent pain after ante grade nailing is common ${ }^{27,28}$. Habemek and Orthner in 1991 reported good results with Seidel's interlocking nail but later withdrew their support in 1998, as they had not assessed the shoulder functions of their patients properly. The cause of pain could be disruption of the rotator cuff in it's avascular zone within $1 \mathrm{~cm}$ of its insertion to the greater tuberosity that may lead to poor healing ${ }^{29}$. 
3 patients had developed shoulder pain/stiffness and 11 of our 20 patients in the interlocking nailing group reported some or the other shoulder pain. Our study confirms that antegrade insertion of nail can lead to problems with shoulder function and range of movement probably because of damage to the rotator cuff.

The sample size of our study is small with only 38 patients included in the final study. The union rates are comparable in both the groups with the results in excellent and good category are similar ( $\mathrm{p}$ value insignificant). There were more fair and poor results in the interlocking nailing group compared to plating group. The complications were more in the interlocking nailing group with most of them pertaining to poor shoulder function or pain and this difference in the complications was statistically significant.

Though interlocking intramedullary nailing is good for specific conditions like pathological fractures, segmental fractures or with associated lower limb fractures which require early weight bearing with crutch walking, we still consider plate osteosynthesis is better than interlocking nailing in treating fractures of the diaphysis of the humerus.

\section{Conclusion}

1. We are of the opinion that the operative treatment of the humerus fractures should be done in patients with polytrauma and in patients with failed conservative treatment.

2. Both the modalities of treatment i.e. plate osteosynthesis and interlocking nailing are good as far as union of the fracture is concerned, but considering the functional outcome and rate of complications, we are of the opinion that plating offers better result than interlocking nailing with respect to pain and function of the shoulder joint.

3. We therefore conclude that in cases where both plating and interlocking nailing can be done, we would prefer to use plating, as the results are better than interlocking nailing.

The fallacies in our study are, the sample size is small and we have not taken retrograde interlocking nailing in to consideration.

\section{References}

[1]. Rose SH, Melton LJ, Morrey BF, Ilstrup DM, Riggs BL. Epidemiologic features of humeral fractures, Clin.Orthop Relat Res. 1982 Aug; (168): 24-30.

[2]. Rockwood CA, Bucholz RW, Green DP, Heckman JD, Rockwood and Green's Fractures In Adults, Vol 1, 4th Edition, Lippincott Raven; 1996.

[3]. Buckholz RW, Heckman JD, Rockwood, Green's. Fractures in Adults. Vol 1, 5th Edition.Lippincott Williams and Wilkins; 2001.

[4]. Rockwood CA, Bucholz RW, Green DP, Heckman JD, Rockwood and Green's Fractures In Adults, Vol 1, 4th Edition, Lippincott Raven; 1996

[5]. Gustilo RB, Kyle RF, Templeman D fractures and dislocations. Ist edition Mosby publications; 1993

[6]. Rockwood CA, Bucholz RW, Green DP, Heckman JD, Rockwood and Green's Fractures In Adults, Vol 1, 4th Edition, Lippincott Raven; 1996

[7]. Atroshi I, Gummesson I, Andersson B, Dahlgr E, Johannson A. The disabilities of the arm, shoulder and hand (DASH) outcome questionnaire.ActaOrthopScand , BMC Musculoskelet Disord.2006;7:44.

[8]. Gummesson C, Atroshi I, Ekdahl C. BMC Musculoskeletal Disorders 2003,4:11

[9]. Michael MW, Tracy 1, Winston, Vucy, Schemitsch. Functional Outcome Following Surgical Treatment of Intra-Articular Distal Humeral Fractures Through a Posterior Approach. Volume 82-A (12), December 2000, 170111707.

[10]. Ruedi T, Moshfeigh A, Pfieffer K, Allgower M. Fresh fractures of the shaft of the humerus. - Conservative or operative treatment? ReconstionSurg and trauma. 14.65-74.1974

[11]. Foster RJ, Dixon GL, Bach A W, Appleyard RW, Green TM. Internal Fixation of fractures and non union of the humerus shaft JBJS; Vol 67A; No. 6, July 1985; 857-64

[12]. Bell MJ, Beauchamp, Kellam JK and McMurtry. The Results of Plating Humeral Shaft Fractures in Patients with Multiple Injuries, the Sunny Brook Experience. JBJS Am 1985; Vol- 67; 293-296

[13]. McCormack RG, Brien D, Buckley RE, McKee, Powell J, Schemitsch EH.fixation of fracture of shaft of humerus by dynamic compression plate or Intramedullary nail, J Bone Joint Surgery (Br) Toronto Canada, 2000; 82- B: 336-9.

[14]. Naiman PT, Schein AJ, Siffert RS. Use of ASIF compression plates in selected shaft fractures of the upper extremity. A preliminary report ClinOrthop. $71: 208-2.16 .1970$

[15]. Pollock FH, Drake D, Bovill EG, et al. treatment of radial neuropathy associated with fracture shaft of humerus. JBJS (A) 1981; 63: 239-243

[16]. Dabezies EJ, Banta CJ, Murphy CP, d'Ambrosia RD. Plate fixation of the humeral shat for acute fractures with or without radial nerve injuries. J Orthop Trauma: 1992:6:10-13

[17]. Heim D, Herkert F, Hess P, Regazzoni P. surgical treatment of humeral shaft fractures: the Basel experience. J Traunla: 1993: 35:226-232

[18]. Rommcns PM., Verbrungen J, Bros PL. R trograde locked nailing of humeral shaft fractures. J. Bone Joint Surg (Br) 1995; 77B: 84-89.

[19]. Ruedi T, Moshfeigh A, Pfieffer K, Allgower M. Fresh fractures of the shaft of the humerus. - Conservative or operative treatment? ReconstionSurg and trauma. 14.65-74.1974

[20]. Hems TE, Bhullar TP. Interlocking nailing of humeral shaft fractures: the Oxford experience 1991-1994. Injury 1996:27:485-489

[21]. Crolla RMPH, deVries LS, Clevers CJ. Locked intramedullary nailing of humeral fractures injury 1993; 24: 403-455

[22]. Ingman AM, Waters DA. Locked intramedullary .. nailing of humeral shaft . fractures. JBJS Br 1994:76-6: 23-24

[23]. Garcia AJ, 1aeck BH.Radial nerve injuries in the fracturcs of the shaft of the humerus. Am J Surg. 1960:99:625-627

[24]. Kettlekamp DB, Alexander H. Clinical review of radial nerve injury. J trauma. 1967; 7:424-432

[25]. Rathbun JB, Macnab LThe microvascular pattern of the rotator cuff. JBJSSB: 1970: 52-B. 540-553 
[26]. Muller ME, Algower M, Schneider R, Willenegger H. Manual of internal fixation. Springer- V erlag.3rd Edition; 1991

[27]. Bain G, Sandow M. treatment of humcral shaft fractures with the Seidel intramedullary nail. JBJS Br. 1992; 74-b supp. I. 39-40

[28]. Titze A, the operative treatment of the fractures of the shaft of the humerus, Recons. Surg. \& Traumatol 1974;14:75-83.

[29]. Robinson CM, Bell KM, Court-Brown CM, McQueen MM. Locked nailing of humeral shaft fractures. JBJS-(A): 1992: 74-A: 558-562

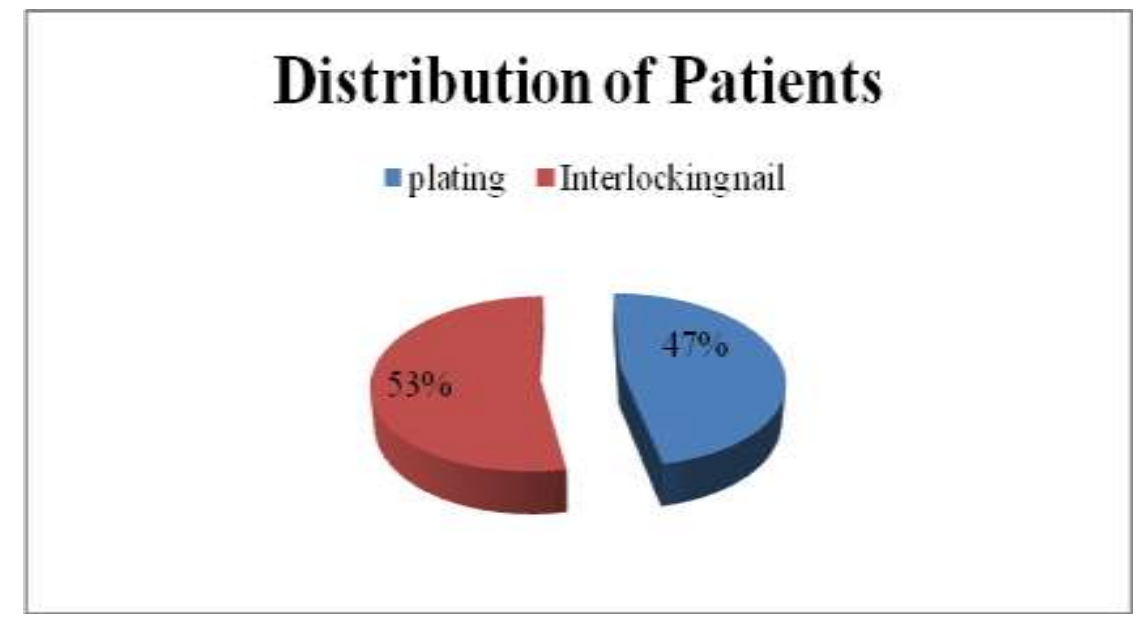

Graph 1

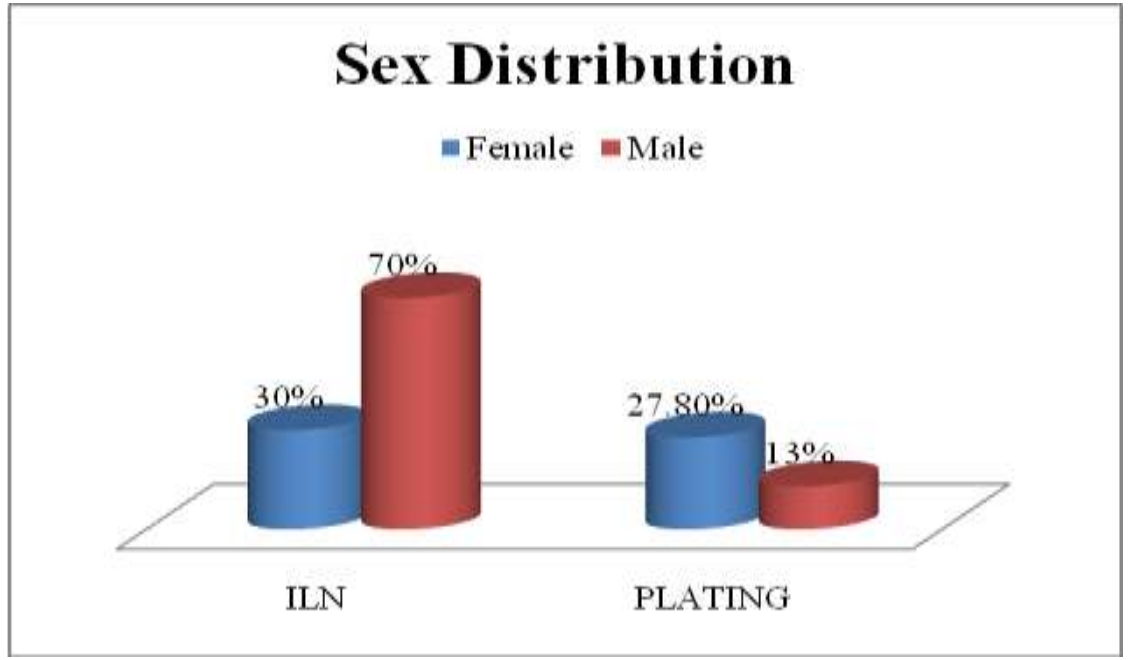

Graph 2

\section{Age of the Patients}

- Mean

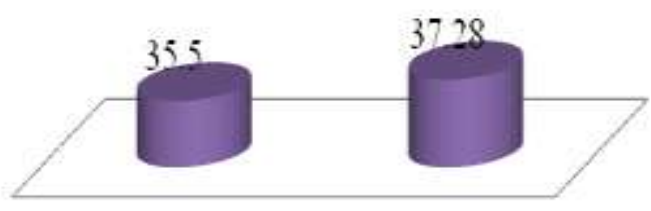

ILN PLATING

\section{Graph 3}




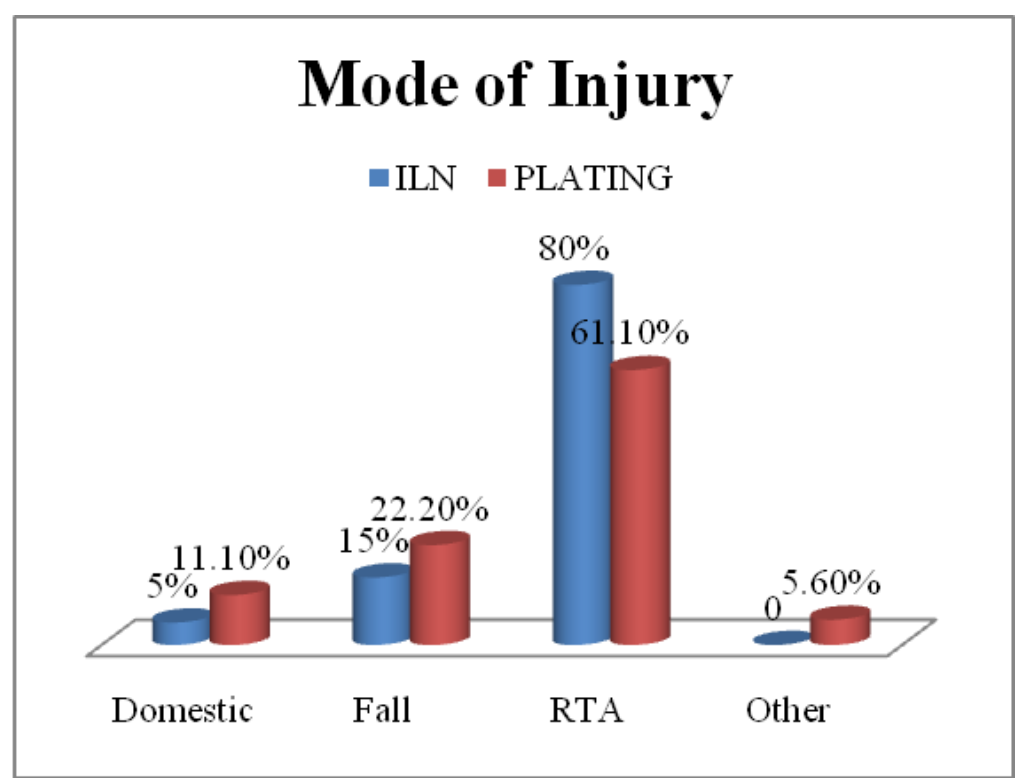

Graph 4

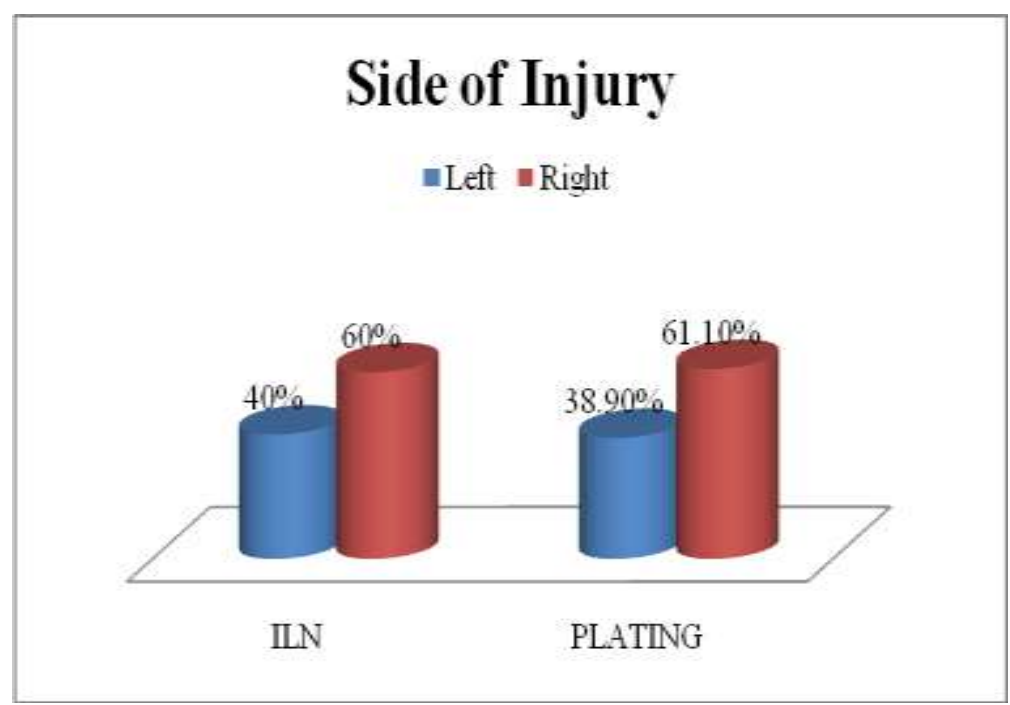

Graph 5

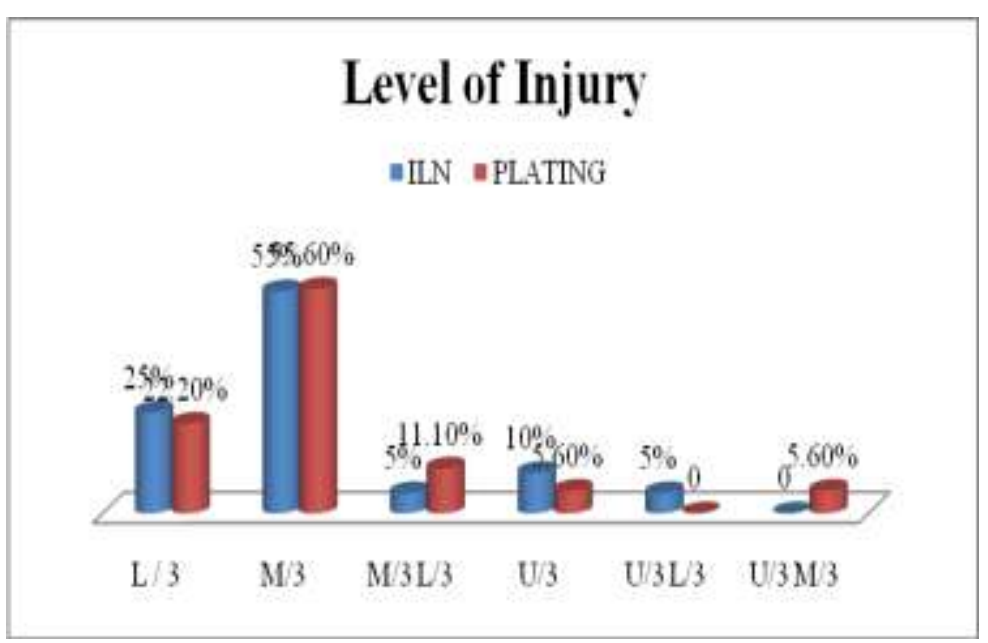

Graph 6 


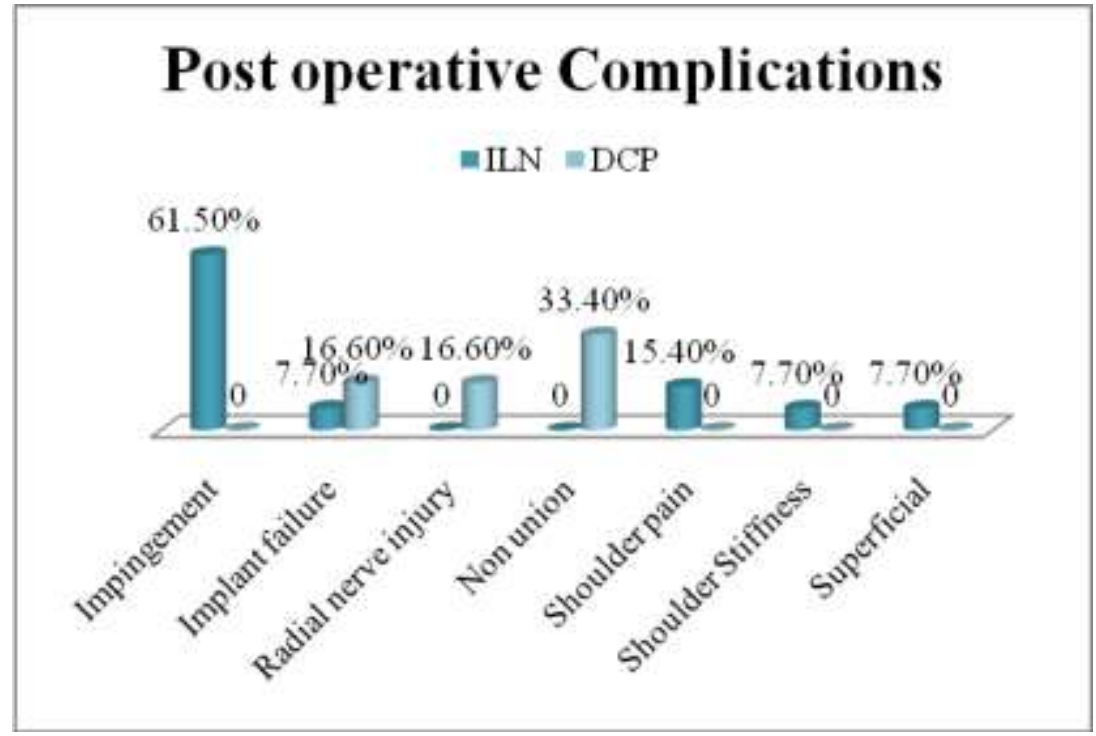

Graph 7

Table 1

\begin{tabular}{|l|l|l|}
\hline plating & Interlocking nail & Total \\
\hline $18(47 \%)$ & $20(53 \%)$ & $38(100 \%)$ \\
\hline
\end{tabular}

Table - 2

\begin{tabular}{|l|l|l|l|}
\hline \multirow{2}{*}{ Sex } & Group & \multirow{2}{*}{ Total } \\
\cline { 2 - 3 } & ILN & PLATING & \\
\hline Female & $6(30 \%)$ & $5(27.8 \%)$ & $11(28.9 \%)$ \\
\hline Male & $14(70 \%)$ & $13(13 \%)$ & $27(71.21 \%)$ \\
\hline Total & $20(100 \%)$ & $18(100 \%)$ & $38(100 \%)$ \\
\hline
\end{tabular}

Table 3

\begin{tabular}{|l|l|l|l|l|l|}
\hline \multicolumn{2}{|l|}{ Group } & N & Mean & Sid Deviation & \\
\hline Age & ILN & 20 & 35.5 & 11.441 & $\mathrm{~T}=0.606$ \\
\hline & PLATING & 18 & 37.28 & 11.187 & $\mathrm{P}=0.549, \mathrm{NS}$ \\
\hline
\end{tabular}

Table 4: Mode Of Injury

\begin{tabular}{|l|l|l|l|}
\hline \multirow{2}{*}{ Mode of Injury } & Group & \multirow{2}{*}{ Total } \\
\cline { 2 - 3 } & ILN & PLATING & \\
\hline Domestic & $1(5 \%)$ & $2(11.1 \%)$ & $3(7.9 \%)$ \\
\hline Fall & $3(15 \%)$ & $4(22.2 \%)$ & $7(18.4 \%)$ \\
\hline RTA & $16(80 \%)$ & $11(61.1 \%)$ & $27(71.1 \%)$ \\
\hline Other & 0 & $1(5.6 \%)$ & $1(2.6 \%)$ \\
\hline Total & $20(100 \%)$ & $18(100 \%)$ & $38(100 \%)$ \\
\hline
\end{tabular}

Table 5: Side Of Injury

\begin{tabular}{|l|l|l|l|}
\hline \multirow{2}{*}{ Side } & Group & \multirow{2}{*}{ Total } \\
\cline { 2 - 3 } & ILN & PLATING & \\
\hline Left & $81(40 \% \%)$ & $7(38.9 \%)$ & $15(39.5 \%)$ \\
\hline Right & $12(60 \%)$ & $11(61.1 \%)$ & $23(60.5 \%)$ \\
\hline Total & $20(100 \%)$ & $18(100 \%)$ & $38(100 \%)$ \\
\hline
\end{tabular}

Table 6: Level Of Injury

\begin{tabular}{|l|l|l|l|}
\hline \multirow{2}{*}{ Site } & Group & \multirow{2}{*}{ Total } \\
\cline { 2 - 3 } & ILN & PLATING & \\
\hline $\mathrm{L} / 3$ & $5(25 \%)$ & $4(22.2 \%)$ & $9(23.7 \%)$ \\
\hline $\mathrm{M} / 3$ & $11(55 \%)$ & $10(55.6 \%)$ & $21(55.3 \%)$ \\
\hline $\mathrm{M} / 3 \mathrm{~L} / 3$ & $1(5 \%)$ & $2(11.1 \%)$ & $3(7.9 \%)$ \\
\hline $\mathrm{U} / 3$ & $2(10 \%)$ & $1(5.6 \%)$ & $3(7.9 \%)$ \\
\hline $\mathrm{U} / 3 \mathrm{~L} / 3$ & $1(5 \%)$ & 0 & $1(2.6 \%)$ \\
\hline $\mathrm{U} / 3 \mathrm{M} / 3$ & 0 & $1(5.6 \%)$ & $1(2.6 \%)$ \\
\hline Total & $20(100 \%)$ & $18(100 \%)$ & $38(100 \%)$ \\
\hline
\end{tabular}


Plating/Nailing The Ideal Fixation For Diaphyseal Fractures Of Humerus- Our Experience.

Table 7: Statistical Analysis Of Dash Scores

\begin{tabular}{|l|l|l|l|l|l|l|l|}
\hline & $\mathrm{N}$ & Minimum & Maximum & Mean & Sid Deviation & $\begin{array}{l}\text { Mann } \\
\text { whittney } \\
\text { Z value }\end{array}$ & P value \\
\hline Group 1 & 20 & .00 & 92.00 & 43.1000 & 28.12921 & 2.255 & .024 \\
\cline { 1 - 5 } Group 2 & 18 & .00 & 65.00 & 24.0556 & 19.44668 & & sug \\
\hline Total & 38 & .00 & 92.00 & 34.0789 & 25.94108 & & \\
\hline
\end{tabular}

Table 11 Post Operative Complications

\begin{tabular}{|l|l|l|l|}
\hline \multirow{2}{*}{} & Group & \multirow{2}{*}{ Total } \\
\cline { 2 - 3 } & ILN & PLATING & \\
\hline Impingement & $8(61.5 \%)$ & 0 & $8(42.1 \%)$ \\
\hline Implant failure & $1(7.7 \%)$ & $1(16.6 \%)$ & $2(10.5 \%)$ \\
\hline Radial nerve injury & 0 & $1(16.6 \%)$ & $1(5.3 \%)$ \\
\hline Non union & 0 & $2(33.4 \%)$ & $2(10.5 \%)$ \\
\hline Shoulder pain & $2(15.4 \%)$ & 0 & $2(10.5 \%)$ \\
\hline Shoulder Stiffness & $1(7.7 \%)$ & $2(33 . .4 \%)$ & $3(15.8 \%)$ \\
\hline Superficial & $1(7.7 \%)$ & 0 & $1(2.6 \%)$ \\
\hline Total & $13(100 \%)$ & $6(100 \%)$ & $19(100 \%)$ \\
\hline
\end{tabular}

